\title{
Genetic diversity of highly pathogenic H5N8 avian influenza viruses at a single overwintering site of migratory birds in Japan, 2014/15
}

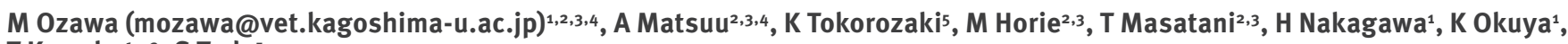
T Kawabata ${ }^{2}$, S Toda 5

1. Laboratory of Animal Hygiene, Joint Faculty of Veterinary Medicine, Kagoshima University, Kagoshima, Kagoshima, Japan

2. Transboundary Animal Diseases Center, Joint Faculty of Veterinary Medicine, Kagoshima University, Kagoshima, Kagoshima, Japan

3. United Graduate School of Veterinary Science, Yamaguchi University, Yamaguchi, Yamaguchi, Japan

4. These authors contributed equally to this work

5. Kagoshima Crane Conservation Committee, Izumi, Kagoshima, Japan

Citation style for this article:

Ozawa M, Matsuu A, Tokorozaki K, Horie M, Masatani T, Nakagawa H, Okuya K, Kawabata T, Toda S. Genetic diversity of highly pathogenic H5N8 avian influenza viruses at a single overwintering site of migratory birds in Japan, 2014/15. Euro Surveill. 2015;20(20):pii=21132. Available online: http://www.eurosurveillance. org/ViewArticle.aspx?Articleld=21132

Article submitted on 11 May 2015 / published on 21 May 2015

We isolated eight highly pathogenic $\mathrm{H}_{5} \mathrm{~N} 8$ avian influenza viruses ( H$_{5} \mathrm{~N} 8$ HPAIVs) in the 2014/15 winter season at an overwintering site of migratory birds in Japan. Genetic analyses revealed that these isolates were divided into three groups, indicating the co-circulation of three genetic groups of $\mathrm{H}_{5} \mathrm{~N} 8$ HPAIV among these migratory birds. These results also imply the possibility of global redistribution of the $\mathrm{H}_{5} \mathrm{~N} 8 \mathrm{HPAIVs}$ via the migration of these birds next winter.

In January 2014, newly discovered highly pathogenic $\mathrm{H}_{5} \mathrm{~N} 8$ avian influenza viruses ( ${ }_{5} \mathrm{~N} 8$ HPAIVs) caused outbreaks in poultry and wild birds in South Korea [1], although their ancestor had been isolated in China in 2013 [2]. Thereafter, these viruses have been circulating in both avian populations in South Korea [3,4] and sporadically in neighbouring countries, including China and Japan. Since November 2014, H5N8 HPAIVs have also appeared in poultry and wild birds in Europe $[5,6]$. Genetic analyses revealed that these isolates were closely related to the $\mathrm{H}_{5} \mathrm{~N} 8$ viruses circulating in Korean birds. More recently, genetically similar HPAIVs also caused outbreaks in various avian species in North America [7]. These findings suggest that the $\mathrm{H}_{5} \mathrm{~N} 8$ viruses have circulated and evolved in migratory birds.

\section{Characteristics of the study area}

The Izumi plain, which is located at the southern tip of Japan's mainland, is a major overwintering site of the white-naped crane (Grus vipio) and hooded crane (Grus monacha), both of which are categorised as vulnerable species on the International Union for Conservation of Nature Red List (Figure 1).
Over 10,000 cranes visit this plain in the winter season (arriving around November to December and leaving around February to March). For the purpose of protecting these endangered bird species, the local government creates artificial wet paddy areas for roosting cranes every winter. In addition to the cranes, many other migratory birds including wild ducks, a natural reservoir of influenza $A$ viruses [8], also overwinter at this plain and share the wet paddies. Avian influenza viruses are therefore likely to be transmitted among the migratory birds, including the endangered cranes, at the Izumi plain. In fact, $\mathrm{H}_{5} \mathrm{~N}_{1}$ HPAIVs were isolated from seven dead cranes in the 2010/11 winter season [9]. We have also isolated low pathogenic avian influenza viruses from duck faeces and the cranes' roost water collected at this area over the last two winter seasons (data not shown).

\section{Influenza isolates from birds in the study area}

On 23 November 2014, a debilitated white-naped crane was captured at the Izumi plain. Tracheal and cloacal swabs were collected and subjected to RNA extraction for the detection of influenza A viral genes and inoculation into embryonated chicken eggs for virus isolation. Influenza A viral M gene was detected in the RNA from the tracheal swab by conventional reverse transcription PCR. The allantoic fluids of the inoculated eggs showed haemagglutination activity. Further genetic analyses of the allantoic fluid revealed that the isolate was the $\mathrm{H}_{5} \mathrm{~N} 8$ subtype influenza A virus. The infected white-naped crane died on 29 November 2014; investigations are under way into the cause of death. The partial sequence of the haemagglutinin (HA) gene revealed that the isolate encoded RERRRKR.G at the 


\section{FIGURE 1}

Map of crane flyways around the Izumi plain, Japan, 2014/15
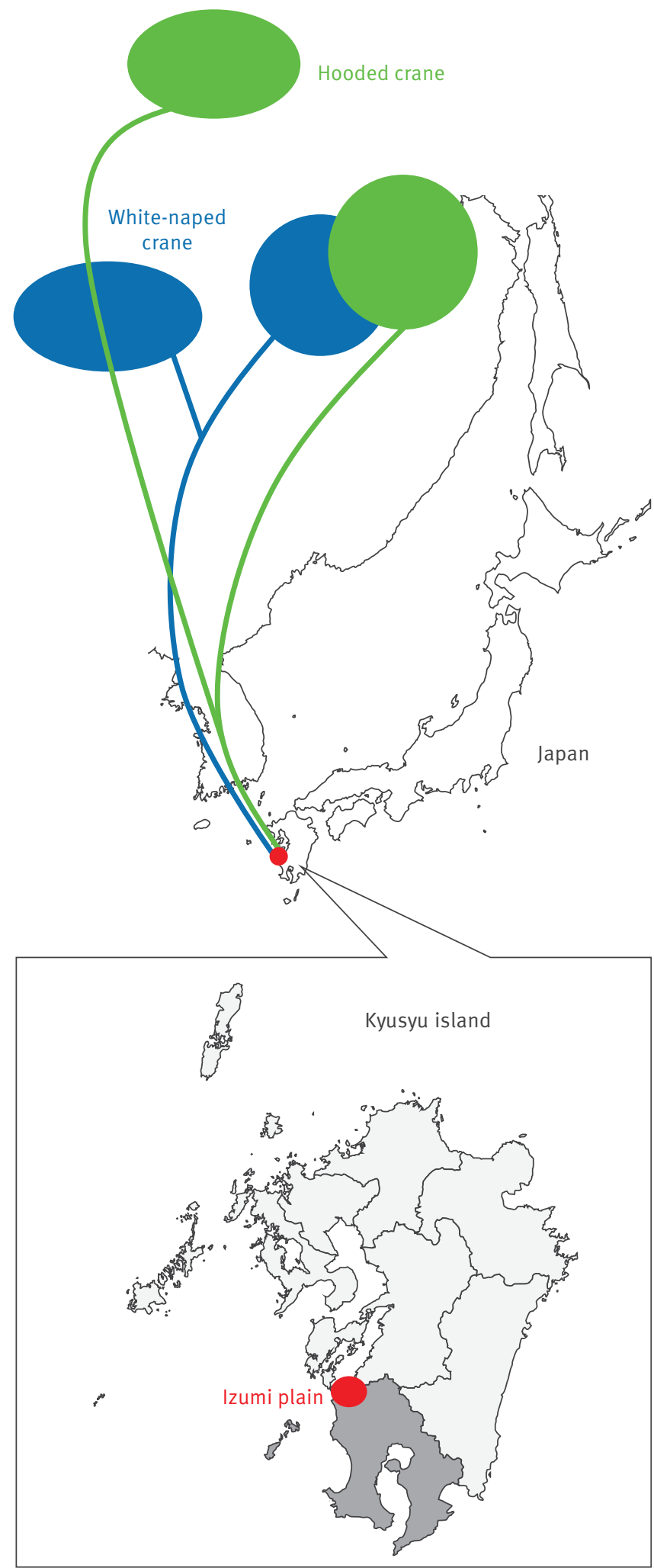

The location of the Izumi plain is indicated in red circles. Breeding grounds (circles) and flyways (lines) of the white-naped crane (blue) and hooded crane (green) are also shown

HA cleavage sites, suggesting their potential to cause systemic infection, subsequently leading to high pathogenicity.
Since 23 November 2014 when the infected crane was found, wild birds within a $10 \mathrm{~km}$ radius of the point where the infected crane was found have been placed under active surveillance for HPAIVs. Local government staff searched for sick and dead wild birds in the area, and sent us the swab specimens and/or dead bodies to test for avian influenza viruses. As of 21 March 2015, eight $\mathrm{H}_{5} \mathrm{~N} 8 \mathrm{HPAIV}$ s have been isolated from six debilitated or dead cranes, two dead mallard ducks (Anas platyrhynchos) and a water sample collected from the cranes' roost at the Izumi plain (Table 1 ). These virus isolations were reported in a timely manner to the World Organisation for Animal Health via the Ministry of Agriculture, Forestry and Fisheries of Japan [10].

To genetically characterise these $\mathrm{H}_{5} \mathrm{~N} 8$ HPAIV isolates, we determined the complete genome sequences of the eight $\mathrm{H}_{5} \mathrm{~N} 8$ HPAIV isolates, and deposited the sequences in the Global Initiative on Sharing Avian Influenza Data (GISAID) database (Table 2). Overall sequence data show that each gene segment of these isolates was genetically similar to the counterpart $\mathrm{H}_{5} \mathrm{~N} 8 \mathrm{HPAIV}$ recently isolated elsewhere in the world, suggesting that these isolates had not experience gene reassortment since their parental viruses caused outbreaks in South Korea in early 2014.

\section{Phylogenetic analysis}

To understand the genetic relationship between our isolates and related viruses, the $\mathrm{HA}$ and neuraminidase (NA) genes were phylogenetically analysed with counterparts from the representative avian influenza $\mathrm{H}_{5}$ (Figure 2A) and N8 (Figure 2B) subtypes, respectively. We found that the $\mathrm{H}_{5}$ genes from our eight isolates belonged to clade 2.3.4.4 and were genetically divided into three groups. The water isolate, A/ environment/Kagoshima/KU-ngr-H/2014( $\left.\mathrm{H}_{5} \mathrm{~N} 8\right)$, fell into a phylogenetic cluster together with the European isolates and was closely related to two wild duck isolates in Japan (Group $A$, indicated in green in the Figures). The first and second crane isolates, $\mathrm{A} / \mathrm{crane} /$ Kagoshima/KU1/2014(H5N8) and A/crane/Kagoshima/ $\mathrm{KU}_{13} / 2014\left(\mathrm{H}_{5} \mathrm{~N} 8\right)$, were genetically similar to the North American isolates (Group B, blue in the Figures). The HA genes of the rest of our isolates (Group C, red in the Figures), as well as a poultry isolate from Japan were clearly distinct from those of the other recent $\mathrm{H}_{5} \mathrm{~N} 8$ isolates. These findings suggest that three genetically distinct groups of $\mathrm{H}_{5} \mathrm{~N} 8$ HPAIVs were independently circulating among the migratory birds at the Izumi plain. Intriguingly, the genetic grouping of our isolates matched broadly the dates of sampling; the forth to eighth isolates were categorised into Group C, while earlier isolates were categorised into Group A or B. To determine whether this virus group has genetic characteristics that become predominant among the migratory birds over the remaining virus groups, further investigation would be needed.

To further characterise the three genetic groups of $\mathrm{H}_{5} \mathrm{~N} 8$ HPAIVs, the nucleotide sequences of the remaining six 
genes were phylogenetically analysed with their counterparts from the representative avian viruses of various subtypes (Figure 2).

The bootstrap values between the isolates in Groups $A$ and $C$ and among the isolates in Group $B$ in the phylogenetic trees of the $\mathrm{PB}_{2}$ (Figure $3 \mathrm{~A}$ ) and $\mathrm{PB}_{1}$ (Figure $3 B$ ) genes were $100 \%$. Similarly, the bootstrap value between the isolates in Group $A$ and the isolates in Groups $B$ and $C$ in the phylogenetic tree of the NS genes (Figure $3 \mathrm{~F}$ ) were $99 \%$. These results support our findings in the phylogenetic trees of the HA and NA genes.

No mutations were found that are known to confer the ability to infect mammalian hosts or to provide resistance against anti-influenza drugs to avian influenza viruses, with the exception of an asparagine at position 31 in the $M_{2}$ protein, which confers resistance to the $\mathrm{M}_{2}$ ion channel blocker amantadine [11].

\section{Conclusion}

We isolated eight $\mathrm{H}_{5} \mathrm{~N} 8$ HPAIVs from migratory birds and the water in their environment at the Izumi plain in southern Japan. Based on their genome sequences, these isolates were genetically divided into three groups. These results indicate the co-circulation of at least three genetic groups of $\mathrm{H}_{5} \mathrm{~N} 8$ HPAIVs among the migratory birds overwintering at a single site in Japan. These $\mathrm{H}_{5} \mathrm{~N} 8$ HPAIVs are most likely to be derived from wild ducks [12], rather than from cranes whose flyways were restricted to East Asian countries (Figure $1 A)$. These findings also imply the possibility of global redistribution of the $\mathrm{H}_{5} \mathrm{~N} 8$ HPAIVs via migration of these ducks next winter.

TABLE 1

H5N8 influenza A viruses isolated in this study, Izumi plain, Japan, 2014/15 ( $=8$ )

\begin{tabular}{|c|c|c|c|}
\hline Isolate & Collection date & Host & Specimen source \\
\hline A/crane/Kagoshima/KUo.5014 $\left(\mathrm{H}_{5} \mathrm{~N} 8\right)$ & 23 November 2014 & Sick white-naped crane & Tracheal and cloacal swabs \\
\hline A/environment/Kagoshima/KU-ngr-H/2014(H5N8) & 1 December 2014 & $N A^{a}$ & Water sample \\
\hline A/crane/Kagoshima/KU21/2014(H5N8) & 17 December 2014 & Dead hooded crane & Tracheal and cloacal swabs \\
\hline A/crane/Kagoshima/KU41/2014(H5N8) & 24 December 2014 & Dead hooded crane & Tracheal and cloacal swabs \\
\hline A/crane/Kagoshima/KU53/2015(H5N8) & 3 January 2015 & Dead hooded crane & Tracheal and cloacal swabs \\
\hline A/mallard duck/Kagoshima/KU70/2015(H5N8) & 14 January 2015 & Dead mallard duck & Conjunctival swab \\
\hline A/mallard duck/Kagoshima/KU116/2015(H5N8) & 13 February 2015 & Dead mallard duck & Conjunctival swab \\
\hline
\end{tabular}

a NA, not applicable. 
TABLE 2

Nucleotide identity of the H5N8 influenza A isolates and their closest relatives, Izumi plain, Japan, 2014/15 (n = 8)

\begin{tabular}{|c|c|c|c|c|}
\hline Isolate & Gene & Accession number ${ }^{\mathrm{a}}$ & Closest relative $^{b}$ & Identity (\%) \\
\hline \multirow{8}{*}{$\begin{array}{l}\text { A/crane/Kagoshima/ } \\
\text { KU0.5014(H5N8) }\end{array}$} & PB2 & EPI553205 & A/gyrfalcon/Washington/41088-6/2014(H5N8) & 99.65 \\
\hline & PB1 & EPI553206 & A/gyrfalcon/Washington/41088-6/2014(H5N8) & 99.43 \\
\hline & PA & EPI553207 & A/Northern pintail/Washington/40964/2014(H5N2) & 99.87 \\
\hline & HA & EPI553208 & A/Northern pintail/Washington/40964/2014(H5N2) & 99.29 \\
\hline & NP & EPI553209 & A/Northern pintail/Washington/40964/2014(H5N2) & 99.53 \\
\hline & NA & EPI553210 & A/guinea fowl/Oregon/41613-1/2014(H5N8) & 98.94 \\
\hline & M & EPI553211 & A/Baikal teal/Korea/Donglim3/2014(H5N8) & 100.00 \\
\hline & NS & EPI553212 & A/Baikal teal/Korea/Donglim3/2014(H5N8) & 99.76 \\
\hline \multirow{8}{*}{$\begin{array}{l}\text { A/environment/Kagoshima/ } \\
\text { KU-ngr-H/2014(H5N8) }\end{array}$} & PB2 & EPI553359 & A/duck/Chiba/26-372-61/2014(H5N8) & 99.78 \\
\hline & PB1 & EPI553360 & A/duck/Chiba/26-372-61/2014(H5N8) & 98.86 \\
\hline & PA & EPI553361 & A/duck/Chiba/26-372-61/2014(H5N8) & 99.81 \\
\hline & HA & EPI553362 & A/duck/Chiba/26-372-61/2014(H5N8) & 99.76 \\
\hline & NP & EPI553363 & A/duck/Chiba/26-372-61/2014(H5N8) & 99.87 \\
\hline & NA & EPI553364 & A/turkey/Germany-MV/R2472/2014(H5N8) & 98.86 \\
\hline & M & EPI553365 & A/duck/Chiba/26-372-61/2014(H5N8) & 100.00 \\
\hline & NS & EPI553366 & A/duck/Chiba/26-372-61/2014(H5N8) & 99.76 \\
\hline \multirow{8}{*}{$\begin{array}{l}\text { A/crane/Kagoshima/ } \\
\text { KU13/2014(H5N8) }\end{array}$} & PB2 & EPI573635 & A/gyrfalcon/Washington/41088-6/2014(H5N8) & 99.52 \\
\hline & PB1 & EPI573636 & A/gyrfalcon/Washington/41088-6/2014(H5N8) & 99.60 \\
\hline & PA & EPI573637 & A/Northern pintail/Washington/40964/2014(H5N2) & 99.44 \\
\hline & $\mathrm{HA}$ & EPI573638 & A/Northern pintail/Washington/40964/2014(H5N2) & 99.53 \\
\hline & NP & EPI573639 & A/gyrfalcon/Washington/41088-6/2014(H5N8) & 99.67 \\
\hline & NA & EPI573640 & A/guinea fowl/Oregon/41613-1/2014(H5N8) & 98.65 \\
\hline & M & EPI573641 & A/Baikal teal/Korea/Donglim3/2014(H5N8) & 99.80 \\
\hline & NS & EPI573642 & A/Baikal teal/Korea/Donglim3/2014(H5N8) & 99.76 \\
\hline \multirow{8}{*}{$\begin{array}{l}\text { A/crane/Kagoshima/ } \\
\text { KU21/2014(H5N8) }\end{array}$} & PB2 & EPI573643 & A/chicken/Miyazaki/7/2014(H5N8) & 99.82 \\
\hline & PB1 & EPI573644 & A/chicken/Miyazaki/7/2014(H5N8) & 99.69 \\
\hline & PA & EPI573645 & A/Baikal teal/Korea/Donglim3/2014(H5N8) & 99.86 \\
\hline & HA & EPI573646 & A/chicken/Miyazaki/7/2014(H5N8) & 99.71 \\
\hline & NP & EPI573647 & A/breeder duck/Korea/H158/2014(H5N8) & 99.73 \\
\hline & NA & EPI573648 & A/chicken/Miyazaki/7/2014(H5N8) & 99.79 \\
\hline & $\mathrm{M}$ & EPI573649 & A/chicken/Miyazaki/7/2014(H5N8) & 99.80 \\
\hline & NS & EPI573650 & A/chicken/Miyazaki/7/2014(H5N8) & 99.76 \\
\hline \multirow{8}{*}{$\begin{array}{l}\text { A/crane/Kagoshima/ } \\
\text { KU41/2014(H5N8) }\end{array}$} & PB2 & EPI573651 & A/chicken/Miyazaki/7/2014(H5N8) & 99.82 \\
\hline & PB1 & EPI573652 & A/chicken/Miyazaki/7/2014(H5N8) & 99.64 \\
\hline & PA & EPI573653 & A/Baikal teal/Korea/Donglim3/2014(H5N8) & 99.81 \\
\hline & $\mathrm{HA}$ & EPI573654 & A/chicken/Miyazaki/7/2014(H5N8) & 99.71 \\
\hline & NP & EPI573655 & A/breeder chicken/Korea/H250/2014(H5N8) & 99.73 \\
\hline & NA & EPI573656 & A/chicken/Miyazaki/7/2014(H5N8) & 99.72 \\
\hline & M & EPI573657 & A/chicken/Miyazaki/7/2014(H5N8) & 99.80 \\
\hline & NS & EPI573658 & A/chicken/Miyazaki/7/2014(H5N8) & 99.88 \\
\hline \multirow{8}{*}{$\begin{array}{l}\text { A/crane/Kagoshima/ } \\
\text { KU53/2015(H5N8) }\end{array}$} & PB2 & EPI573661 & A/chicken/Miyazaki/7/2014(H5N8) & 99.78 \\
\hline & PB1 & EPI573662 & A/chicken/Miyazaki/7/2014(H5N8) & 99.60 \\
\hline & PA & EPI573663 & A/Baikal teal/Korea/Donglim3/2014(H5N8) & 99.81 \\
\hline & $\mathrm{HA}$ & EPI573664 & A/chicken/Miyazaki/7/2014(H5N8) & 99.65 \\
\hline & $\mathrm{NP}$ & EPI573665 & A/chicken/Miyazaki/7/2014(H5N8) & 99.73 \\
\hline & NA & EPI573666 & A/chicken/Miyazaki/7/2014(H5N8) & 99.65 \\
\hline & $\mathrm{M}$ & EPI573667 & A/chicken/Miyazaki/7/2014(H5N8) & 99.80 \\
\hline & NS & EPI573668 & A/chicken/Miyazaki/7/2014(H5N8) & 99.88 \\
\hline \multirow{8}{*}{$\begin{array}{l}\text { A/mallard duck/Kagoshima/ } \\
\text { KU70/2015(H5N8) }\end{array}$} & PB2 & EPI573669 & A/chicken/Miyazaki/7/2014(H5N8) & 99.60 \\
\hline & PB1 & EPI573670 & A/mallard/Korea/H297/2014(H5N8) & 99.60 \\
\hline & PA & EPI573671 & A/Baikal teal/Korea/Donglim3/2014(H5N8) & 99.53 \\
\hline & $\mathrm{HA}$ & EPI573672 & A/chicken/Miyazaki/7/2014(H5N8) & 99.59 \\
\hline & NP & EPI573673 & A/chicken/Miyazaki/7/2014(H5N8) & 99.80 \\
\hline & NA & EPI573674 & A/chicken/Miyazaki/7/2014(H5N8) & 99.72 \\
\hline & $\mathrm{M}$ & EPI573675 & A/chicken/Miyazaki/7/2014(H5N8) & 99.80 \\
\hline & NS & EPI573676 & A/chicken/Miyazaki/7/2014(H5N8) & 99.76 \\
\hline \multirow{8}{*}{$\begin{array}{l}\text { A/mallard duck /Kagoshima/ } \\
\text { KU116/2015(H5N8) }\end{array}$} & PB2 & EPI573677 & A/chicken/Miyazaki/7/2014(H5N8) & 99.56 \\
\hline & PB1 & EPI573678 & $\mathrm{A} / \mathrm{mallard} /$ Korea/H297/2014(H5N8) & 99.52 \\
\hline & PA & EPI573679 & A/Baikal teal/Korea/Donglim3/2014(H5N8) & 99.39 \\
\hline & HA & EPI573680 & A/chicken/Miyazaki/7/2014(H5N8) & 99.59 \\
\hline & NP & EPI573681 & A/chicken/Miyazaki/7/2014(H5N8) & 99.80 \\
\hline & NA & EPI573682 & A/chicken/Miyazaki/7/2014(H5N8) & 99.72 \\
\hline & $M$ & EPI573683 & A/chicken/Miyazaki/7/2014(H5N8) & 99.80 \\
\hline & NS & EPI573684 & A/chicken/Miyazaki/7/2014(H5N8) & 99.88 \\
\hline
\end{tabular}

a Accession numbers in the GISAID (http://platform.gisaid.org/) database are listed.

b Representative viruses with the highest nucleotide identity found in the GISAID and/or GenBank (http://www.ncbi.nlm.nih.gov/genbank/) databases on 23 March 2015 are listed. We thank the authors, originating and submitting laboratories of the sequences from GISAID's Epiflu Database on which this research is based. 


\section{FIGURE 2A}

Phylogenetic trees of the HA and NA genes of the H5N8 HPAIVs isolated at the Izumi plain, Japan, 2014/15 ( $\mathrm{n}=8$ )

\section{(A) HA gene}

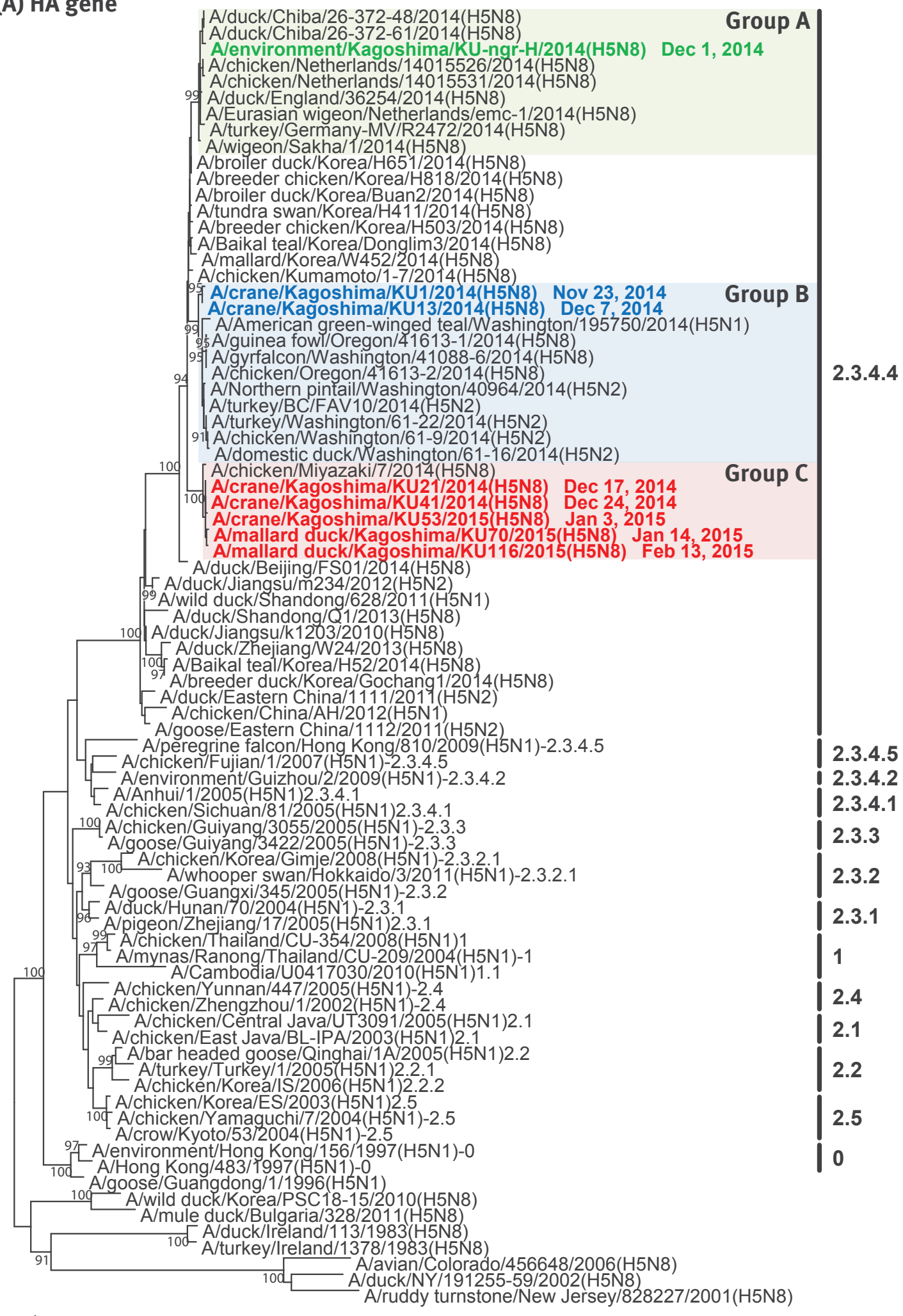

0.02

HA: haemagglutinin; HPAIV: highly pathogenic avian influenza viruses; NA: neuraminidase.

The nucleotide sequences of the HA (A) and NA (B) genes from our $\mathrm{H}_{5} \mathrm{~N} 8$ isolates were phylogenetically analysed with counterparts from other $\mathrm{H}_{5}$ and N8 subtype viruses, respectively, using the neighbour-joining method with a bootstrapping set of 1,000 replicates. Our isolates in Groups A, B and C are indicated in green, blue and red, respectively (see main text for details), with the dates of sampling. Bootstrap values of $>90 \%$ are shown at the nodes. The scale bar indicates the number of nucleotide substitutions per site. 
Phylogenetic trees of the HA and NA genes of the H5N8 HPAIVs isolated at the Izumi plain, Japan, 2014/15 ( $\mathrm{n}=8$ )

\section{(B) NA gene}

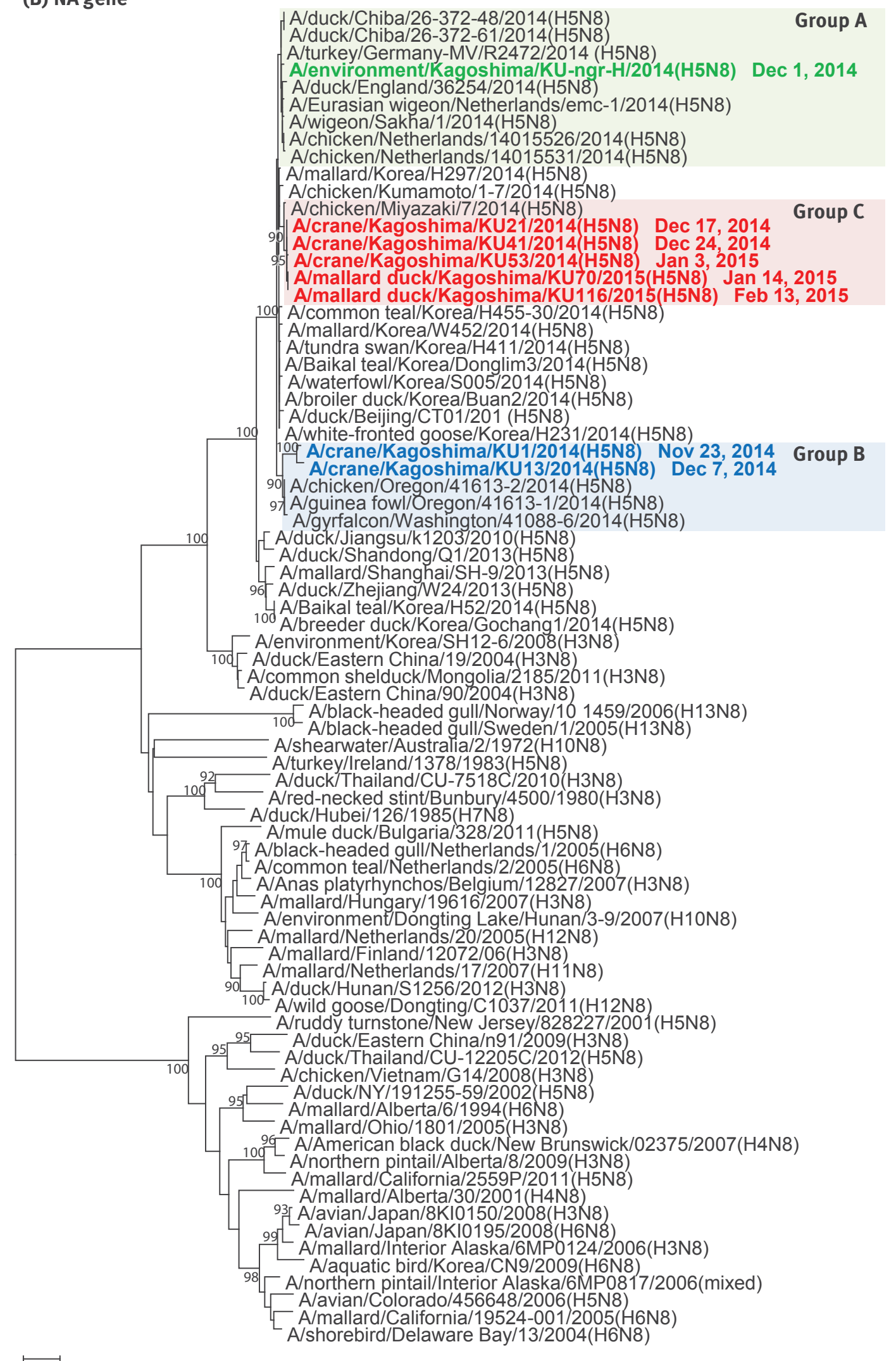

The nucleotide sequences of the HA (A) and NA (B) genes from our $\mathrm{H}_{5} \mathrm{~N} 8$ isolates were phylogenetically analysed with counterparts from other $\mathrm{H}_{5}$ and $\mathrm{N} 8$ subtype viruses, respectively, using the neighbour-joining method with a bootstrapping set of 1,000 replicates. Our isolates in Groups A, B and C are indicated in green, blue and red, respectively (see main text for details), with the dates of sampling. Bootstrap values of $>90 \%$ are shown at the nodes. The scale bar indicates the number of nucleotide substitutions per site. 
(A) PB2 gene

94 A/duck/Chiba/26-372-48/2014(H5N8)

94 A/duck/Chiba/26-372-61/2014(H5N8)

99 Alenvironment/Kagoshima/KU-ngr-H/2014(H5N8)

A/duck/England/36254/14(H5N8)

93 A/chicken/Netherlands/14015526/2014(H5N8)

90 A/chicken/Netherlands/14015531/2014(H5N8)

A/Baikal teal/Korea/Donglim3/2014(H5N8)

A/mallard/Korea/W452/2014(H5N8)

A/chicken/Kumamoto/1-7/2014(H5N8)

A/broiler duck/Korea/Buan2/2014(H5N8)

A/common teal/Korea/H455-30/2014(H5N8)

A/waterfowl/Korea/S005/2014(H5N8)

A/duck/Beijing/FS01/2014(H5N8)

A/mallard/Korea/H297/2014(H5N8)

A/white-fronted goose/Korea/H231/2014(H5N8)

[A/chicken/Miyazaki/7/2014(H5N8)

A/crane/Kagoshima/KU21/2014(H5N8)

A/crane/Kagoshima/KU41/2014(H5N8)

A/crane/Kagoshima/KU53/2015/H5N8

100 . A/mallard duck/Kagoshima/KU70/2015(H5N8

A/mallard duck/Kagoshima/KU116/2015(H5N8)

A/crane/Kagoshima/KU1/2014(H5N8)

A/crane/Kagoshima/KU13/2014(H5N8)

A/American green-winged teal/Washington/195750/2014(H5N1)

100

A/chicken/Oregon/41613-2/2014(H5N8

A/guinea fowl/Oregon/41613-1/2014(H5N8)

A/gyrfalcon/Washington/41088-6/2014(H5N8)

A/turkey/BC/FAV10/2014(H5N2)

A/Northern pintail/Washington/40964/2014(H5N2)

A/turkey/Washington/61-22/2014(H5N2)

A/domestic duckM Washington/61-16/2014(H5N2)

A/chicken/Washington/61-9/2014(H5N2)

A/duck/Shandong/Q1/2013(H5N8)

A/chicken/Jiangsu/cz1/2002(H5N1)

A/chicken/Vietnam/G14/2008(H3N8)

A/shearwater/Australia/2/1972(H1ON8) A/turkey/Ireland/1378/1983(H5N8)

- Alavian/Japan/8KI0150/2008(H3N8)

Alavian/Japan/8KI0195/2008(H6N8)

A/Baikal teal/Korea/H52/2014(H5N8)

$100^{2}$ A/breeder duck/Korea/Gochang1/2014(H5N8)

[ A/duck/Zhejiang/W24/2013(H5NN8)

A/mallard/Shanghai/SH-9/2013(H5N8)

99 A/black-headed gull/Netherlands/1/2005(H6N8)

A/mallard/Netherlands/17/2007(H11N8)

A/dunlin/Sweden/1/2005(H4N6)

A/Anas platyrhynchos/Belgium/12827/2007(H3N8)

A/turkey/ltalyl4169/1999(H7N1)

90 A/duck/Hunan/S1256/2012(H3N8)

A/wild goose/Dongting/C1037/2011(H12N8)

A/aquatic bird/Korea/CN9/2009(H6N8)

A/environment/Dongting Lake/Hunan/3-9/2007(H10N8)

$\mathrm{A} / \mathrm{mallard} / \mathrm{Sw}$ eden/T05011/2009(H4N6)

100- A/northern pintail/Interior Alaska/6MP0817/2006(mixed)

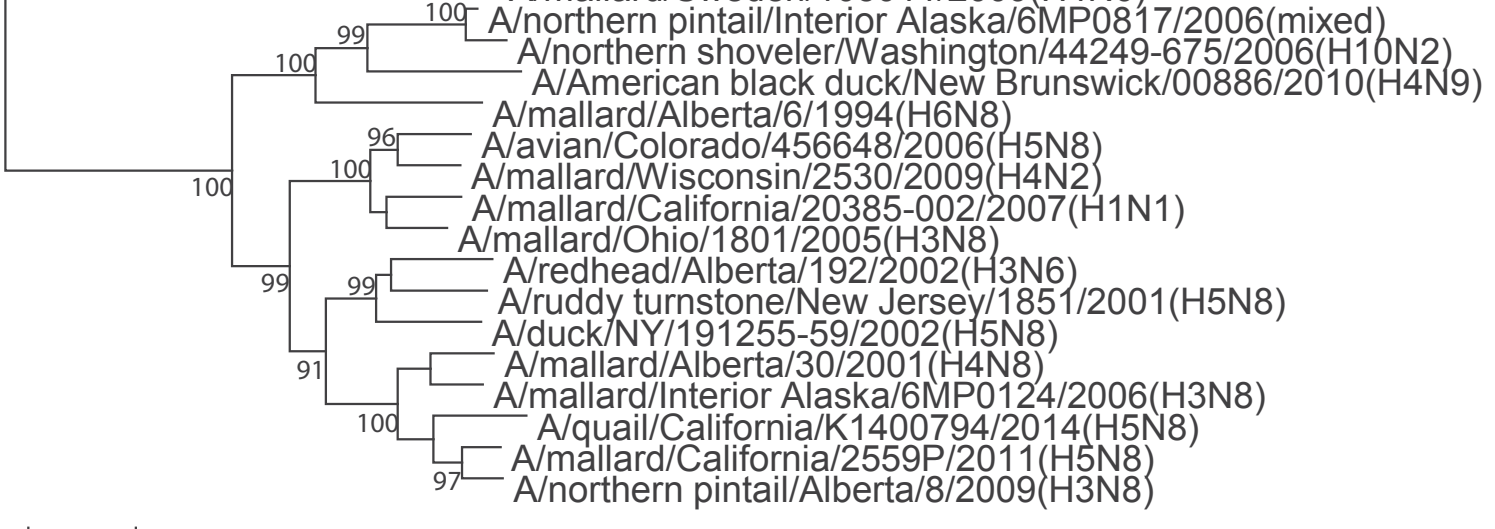

0.02

HPAIV: highly pathogenic avian influenza viruses.

The nucleotide sequences of the $\mathrm{PB}_{2}(\mathrm{~A}), \mathrm{PB}_{1}(\mathrm{~B}), \mathrm{PA}(\mathrm{C}), \mathrm{NP}(\mathrm{D}), \mathrm{M}(\mathrm{E})$ and NS (F) genes from our $\mathrm{H}_{5} \mathrm{~N} 8$ isolates were phylogenetically analysed with counterparts from the representative avian viruses of various subtypes by using the neighbour-joining method with a bootstrapping set of 1,000 replicates. Our isolates in Groups A, B and C are indicated in green, blue and red, respectively (see main text for details). Bootstrap values of $>90 \%$ are shown at the nodes. The scale bar indicates the number of nucleotide substitutions per site. 
Phylogenetic trees of six non-envelope genes of the H5N8 HPAIVs isolated at the Izumi plain, Japan, 2014/15 (n = 8)

\section{(B) PB1 gene}

96 A/duck/Chiba/26-372-48/2014(H5N8)

A/duck/Chiba/26-372-61/2014(H5N8)

9o Alenvironment/Kagoshima/KU-ngr-H/2014(H5N8)

A/chicken/Netherlands/14015526/2014(H5N8)

92 A/chicken/Netherlands/14015531/2014(H5N8)

A/duck/England/36254/2014(H5N8)

A/duck/Beijing/FS01/2014(H5N8)

A/mallard/Korea/W452/2014(H5N8)

A/Baikal teal/Korea/Donglim3/2014(H5N8)

$\mathrm{A} /$ mallard/Korea/H297/2014(H5N8)

A/waterfowl/Korea/S005/2014(H5N8)

A/white-fronted goose/Korea/H231/2014(H5N8)

A/broiler duck/Korea/Buan2/2014(H5N8)

A/common teal/Korea/H455-30/2014(H5N8)

A/chicken/Kumamoto/1-7/2014(H5N8)

8 A/crane/Kagos hima/KU21/2014(H5N8)

A/crane/Kagoshima/KU41/2014(H5N8)

100

A/crane/Kagoshima/KU 53/2015(H5N8)

A/chicken/Miyazaki/7/2014(H5N8)

A/mallard duck/Kagoshima/KU70/2015(H5N8)
A/mallard duck/Kagoshima/KU116/2015(H5N8)

$99-$ Alcrane/Kagoshima/KU1/2014(H5N8)

100 A/crane/Kagoshima/KU13/2014(H5N8)

4 A/gyrfalcon/Washington/41088-6/2014(H5N8)

991 A/guinea fowl/Oregon/41613-1/2014(H5N8)

$\mathrm{A}$ /duck/Shandong/Q1/2013(H5N8)

99 A/Baikal teal/Korea/H52/2014(H5N8)

ag A/breeder duck/Korea/Gochang1/2014(H5N8)

99 A/duck/Zheiliang/W24/2013(H5N8)

A/mallard/Shanghai/SH-9/2013(H5N8)

A/avian/Japan/8KI0150/2008(H3N8)

A/mallard/Interior Alaska/6MP0124/2006(H3N8)

A/chicken/Vietnam/G14/2008(H3N8)

A/turkey/ltaly/4169/1999(H7N1)

A/duck/Hunan/S1256/2012(H3N8)

A/wild goose/Dongting/C1037/2011(H12N8)

A/aquatic bird/Korea/CN9/2009(H6N8)

Alavian/Japan/8K/0195/2008(H6N8)
$109-$ A/black-headed gull/Netherlands/1/2005(H6N8)

100 A/dunlin/Sweden/1/2005(H4N6) 1 (H/Anas platyrhynchos/Belgium/12827/2007(H3N8)

100 A/Anas platyrhynchos/Belgium/12827/2007(H3N8)

A/mallard/Sweden/105011/2009(H4N6)

A/chicken/Jiangsu/cz1/2002(H5N1)

A/turkey/lreland/1378/1983(H5N8)

A/shearwater/Australia/2/1972(H10N8)

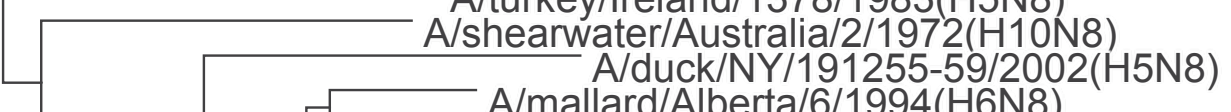

A/mallard/Alberta/6/1994(H6N8)

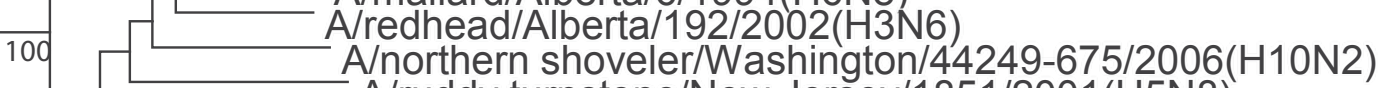

A/ruddy turnstone/New Jersey/1851/2001(H5N8)

$98 \_\mathrm{A} / \mathrm{mallard} /$ California/2559P/2011(H5N8)

A/quail/California/K1400794/2014(H5N8)

A/mallard/Wisconsin/2530/2009/(H4N2)

A/mallard/Ohio/1801/2005(H3N8)
A/avian/Colorado/456648/2006(H5N8)

A/mallard/California/20385-002/2007(H1N1)

A/northern pintail/Alberta/8/2009(H3N8)

A/American black duck/New Brunswick/00886/2010(H4N9)

0.01

A/northern pintail/Interior Alaska/6MP0817/2006(mixed)

HPAIV: highly pathogenic avian influenza viruses.

The nucleotide sequences of the $\mathrm{PB}_{2}(\mathrm{~A}), \mathrm{PB}_{1}(\mathrm{~B}), \mathrm{PA}(\mathrm{C}), \mathrm{NP}(\mathrm{D}), \mathrm{M}(\mathrm{E})$ and NS (F) genes from our $\mathrm{H}_{5} \mathrm{~N} 8$ isolates were phylogenetically analysed with counterparts from the representative avian viruses of various subtypes by using the neighbour-joining method with a bootstrapping set of 1,000 replicates. Our isolates in Groups A, B and C are indicated in green, blue and red, respectively (see main text for details). Bootstrap values of $>90 \%$ are shown at the nodes. The scale bar indicates the number of nucleotide substitutions per site. 


\section{(C) PA gene}

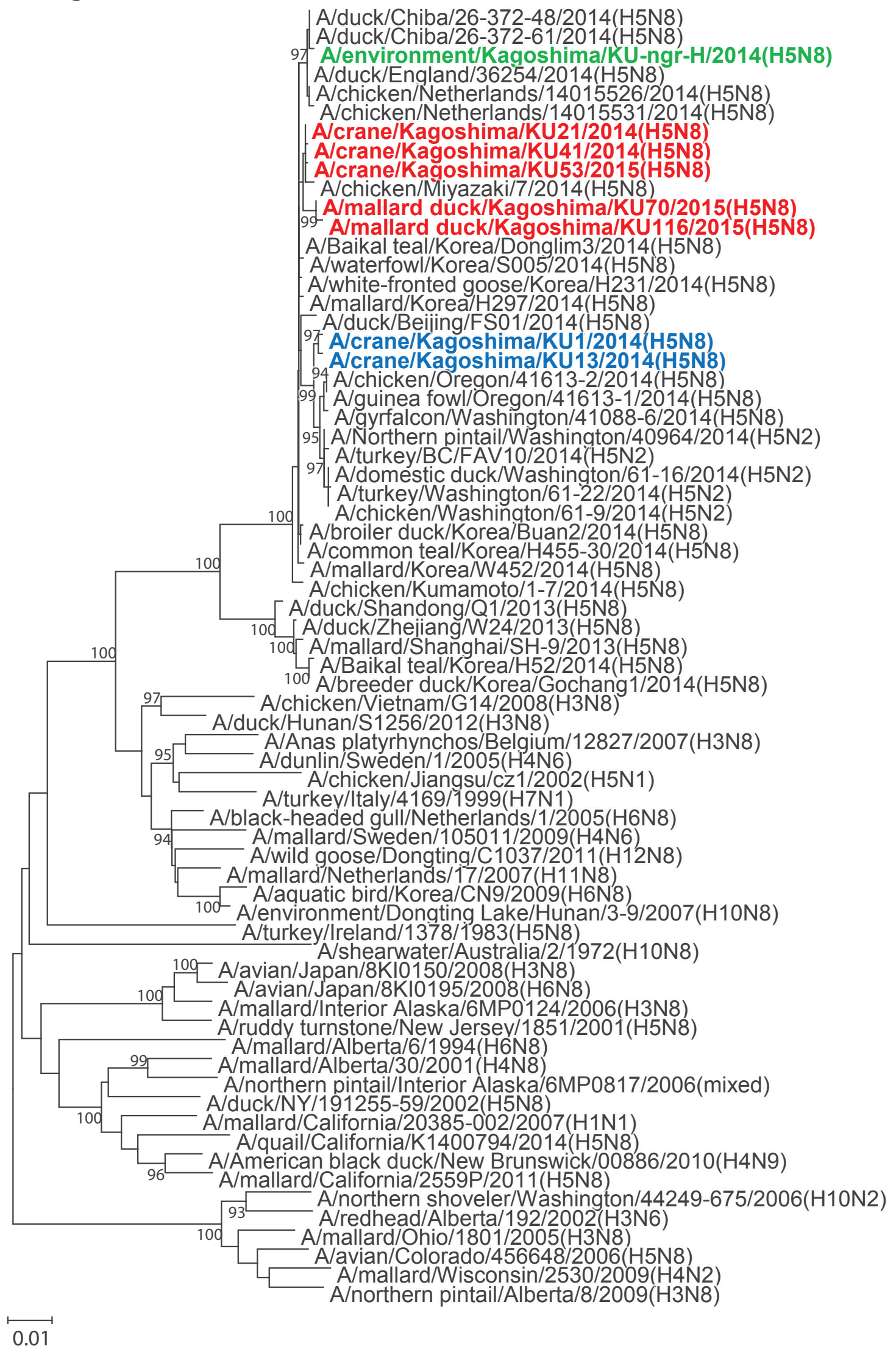

HPAIV: highly pathogenic avian influenza viruses.

The nucleotide sequences of the $\mathrm{PB}_{2}(\mathrm{~A}), \mathrm{PB}_{1}(\mathrm{~B}), \mathrm{PA}(\mathrm{C}), \mathrm{NP}(\mathrm{D}), \mathrm{M}(\mathrm{E})$ and NS (F) genes from our $\mathrm{H}_{5} \mathrm{~N} 8$ isolates were phylogenetically analysed with counterparts from the representative avian viruses of various subtypes by using the neighbour-joining method with a bootstrapping set of 1,000 replicates. Our isolates in Groups A, B and C are indicated in green, blue and red, respectively (see main text for details). Bootstrap values of $>90 \%$ are shown at the nodes. The scale bar indicates the number of nucleotide substitutions per site. 
Phylogenetic trees of six non-envelope genes of the H5N8 HPAIVs isolated at the Izumi plain, Japan, 2014/15 (n = 8)

\section{(D) NP gene}

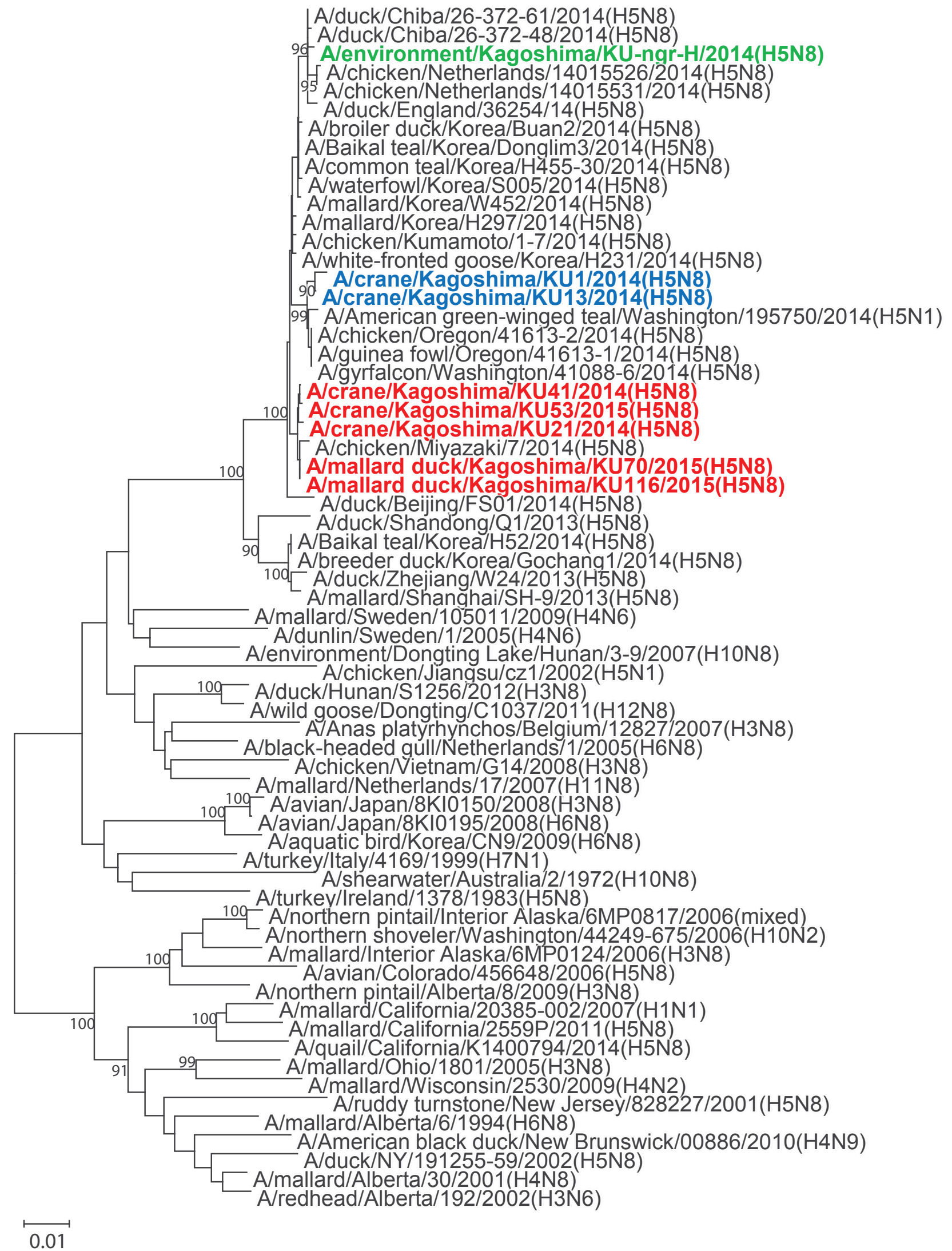

HPAIV: highly pathogenic avian influenza viruses.

The nucleotide sequences of the PB2 (A), PB1 (B), PA (C), NP (D), M (E) and NS (F) genes from our $\mathrm{H}_{5} \mathrm{~N} 8$ isolates were phylogenetically analysed with counterparts from the representative avian viruses of various subtypes by using the neighbour-joining method with a bootstrapping set of 1,000 replicates. Our isolates in Groups A, B and C are indicated in green, blue and red, respectively (see main text for details). Bootstrap values of $>90 \%$ are shown at the nodes. The scale bar indicates the number of nucleotide substitutions per site. 


\section{FIGURE 3E}

Phylogenetic trees of six non-envelope genes of the H5N8 HPAIVs isolated at the Izumi plain, Japan, 2014/15 ( $\mathrm{n}=8$ )

\section{(E) M gene}

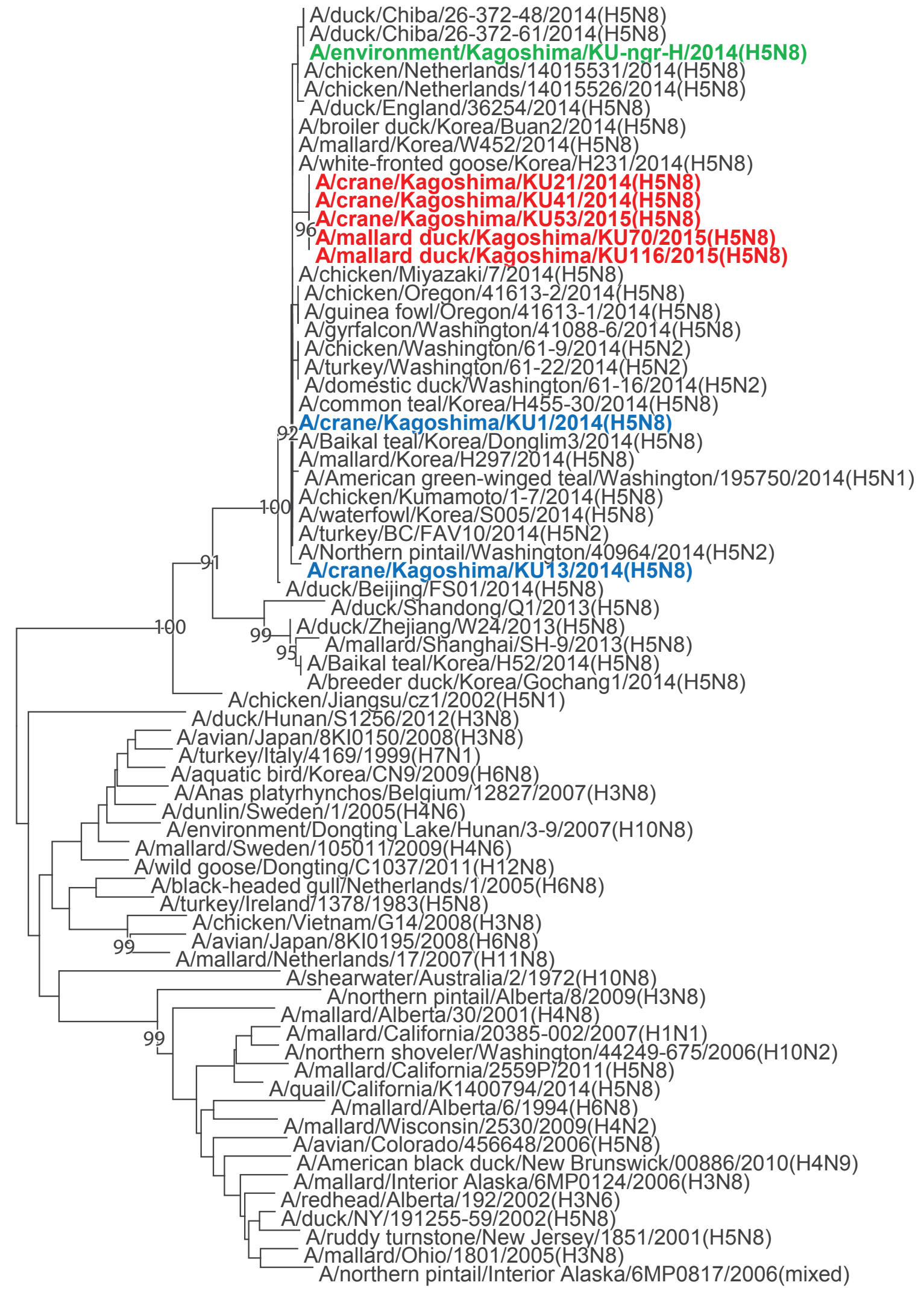




\section{FIGURE 3F}

Phylogenetic trees of six non-envelope genes of the H5N8 HPAIVs isolated at the Izumi plain, Japan, 2014/15 ( $\mathrm{n}=8$ )

\section{(F) NS gene}

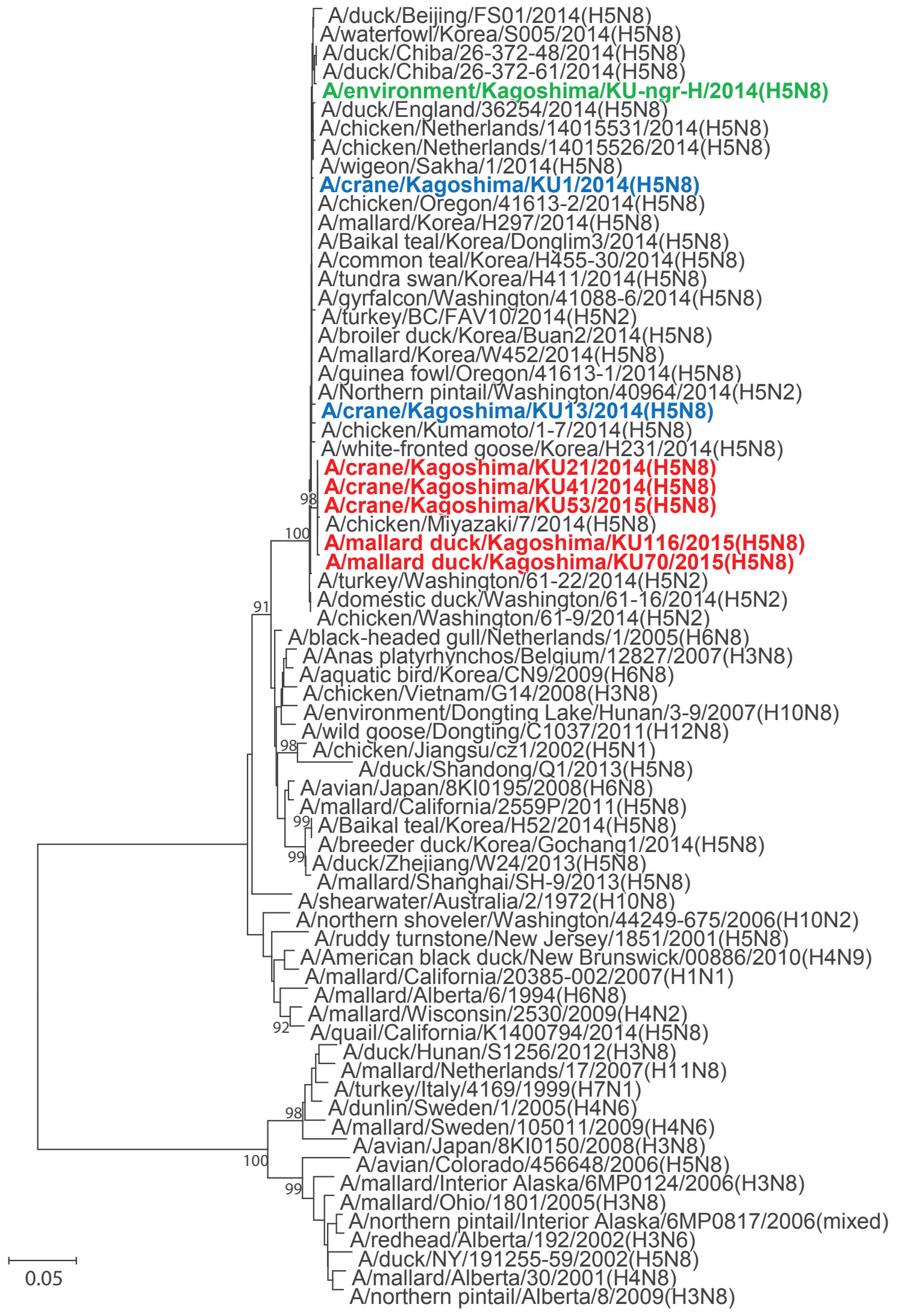

HPAIV: highly pathogenic avian influenza viruses.

The nucleotide sequences of the $\mathrm{PB}_{2}(\mathrm{~A}), \mathrm{PB}_{1}(\mathrm{~B}), \mathrm{PA}(\mathrm{C}), \mathrm{NP}(\mathrm{D}), \mathrm{M}(\mathrm{E})$ and NS (F) genes from our $\mathrm{H}_{5} \mathrm{~N} 8$ isolates were phylogenetically analysed with counterparts from the representative avian viruses of various subtypes by using the neighbour-joining method with a bootstrapping set of 1,000 replicates. Our isolates in Groups A, B and C are indicated in green, blue and red, respectively (see main text for details). Bootstrap values of $>90 \%$ are shown at the nodes. The scale bar indicates the number of nucleotide substitutions per site. 


\section{Acknowledgments}

We thank Lisa M. Burley for editing the manuscript. We thank Satoru Taura, Kotaro Kawabe, Atsushi Nishitani and Naoko Maruta for their technical assistance. We thank the authors, originating and submitting laboratories of the sequences from GISAID's EpiFlu Database on which this research is based (see Table 2 and Figures 2 and 3). All submitters of data may be contacted directly via the GISAID website www. gisaid.org. We thank the Ministry of the Environment, the Prefecture of Kagoshima and the City of Izumi for their kind cooperation. This work was supported by the Grant-in-Aid for Research on Emerging and Re-emerging Infectious Diseases from the Ministry of Health, Labour and Welfare, Japan; by the Grant-in-Aid for Challenging Exploratory Research from the Japan Society for the Promotion of Science (JSPS) (JSPS KAKENHI Grant Number 26670227); by the Grant-in-Aid for Scientific Research (C) from JSPS (JSPS KAKENHI Grant Number 26450430); by Fuji Film Green Fund; by the contracted research activity for crane conservation with the City of Izumi, Japan. This research was commissioned by the Kagoshima Crane Conservation Committee.

\section{Conflict of interest}

None declared.

\section{Authors' contributions}

Makoto Ozawa and Aya Matsuu designed the study; Makoto Ozawa, Aya Matsuu, Kaori Tokorozaki, Masayuki Horie, Tatsunori Masatani, Hiroko Nakagawa, Kosuke Okuya, Toshiko Kawabata, and Shigehisa Toda performed the experiments; Makoto Ozawa drafted the manuscript; Makoto Ozawa, Aya Matsuu, Kaori Tokorozaki, Masayuki Horie, and Tatsunori Masatani reviewed the manuscript.

\section{References}

1. Lee YJ, Kang HM, Lee EK, Song BM, Jeong J, Kwon YK, et al. Novel reassortant influenza $A\left(\mathrm{H}_{5} \mathrm{~N} 8\right)$ viruses, South Korea, 2014. Emerg Infect Dis. 2014;20(6):1087-9. http://dx.doi. org/10.3201/eid2006.140233 PMID:24856098

2. Wu H, Peng X, Xu L, Jin C, Cheng L, Lu X, et al. Novel reassortant influenza $A\left(\mathrm{H}_{5} \mathrm{~N} 8\right)$ viruses in domestic ducks, eastern China. Emerg Infect Dis. 2014;20(8):1315-8. http:// dx.doi.org/10.3201/eid2008.140339 PMID:25075453

3. Ku KB, Park EH, Yum J, Kim JA, Oh SK, Seo SH. Highly pathogenic avian influenza $\mathrm{A}\left(\mathrm{H}_{5} \mathrm{~N} 8\right)$ virus from waterfowl, South Korea, 2014. Emerg Infect Dis. 2014;20(9):1587-8. http:// dx.doi.org/10.3201/eid2009.140390 PMID:25152954

4. Jeong J, Kang HM, Lee EK, Song BM, Kwon YK, Kim HR, et al. Highly pathogenic avian influenza virus ( $\left.\mathrm{H}_{5} \mathrm{~N} 8\right)$ in domestic poultry and its relationship with migratory birds in South Korea during 2014. Vet Microbiol. 2014;173(3-4):249-57. http:// dx.doi.org/10.1016/j.vetmic.2014.08.002 PMID:25192767

5. Bouwstra R, Heutink R, Bossers A, Harders F, Koch G, Elbers A.

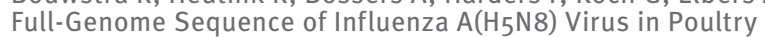
Linked to Sequences of Strains from Asia, the Netherlands, 2014. Emerg Infect Dis. 2015;21(5):872-4. http://dx.doi. org/10.3201/eid2105.141839 PMID:25897965

6. Hanna A, Banks J, Marston DA, Ellis RJ, Brookes SM, Brown IH. Genetic Characterization of Highly Pathogenic Avian Influenza ( $\left.\mathrm{H}_{5} \mathrm{~N} 8\right)$ Virus from Domestic Ducks, England, November 2014. Emerg Infect Dis. 2015;21(5):879-82. http://dx.doi.org/10.3201/ eid2105.141954 PMID:25898126

7. Jhung MA, Nelson DI; Centers for Disease Control and Prevention (CDC). Outbreaks of avian influenza $A\left(\mathrm{H}_{5} \mathrm{~N}_{2}\right)$, $\left(\mathrm{H}_{5} \mathrm{~N} 8\right)$, and $\left(\mathrm{H}_{5} \mathrm{~N}_{1}\right)$ among birds--United States, December 2014-January 2015. MMWR Morb Mortal Wkly Rep. 2015;64(4):111. PMID:25654614

8. Wright PF, Neumann G, Kawaoka Y. Orthomyxoviruses. In: Knipe DM, Howley PM, Griffin DE, Lamb RA, Martin MA, Roizman B, et al., editors. Fields Virology. 2. Fifth ed. Philadelphia, Baltimore, New York, London, Buenos Aires, Hong Kong, Sydney, Tokyo: Wolters Kluwer; Lippincott Williams \& Wilkins; 2007. p. 1691-740
9. World Organisation for Animal Health (OIE). Followup report No. 11. Report reference: 10746; 29 Jun 2011. Available from: http://web.oie.int/wahis/reports/en fup_0000010746_20110629_171928.pdf

10. World Organisation for Animal Health (OIE). Follow-up report No. 15. Report reference: 17219; 20 Feb 2015. Available from: http://www.oie.int/wahis_2/public $\% 5$ C. $\% 5$ Ctemp $\% 5$ Creports/ en_fup_0000017219_20150220_144318.pdf

11. Hay AJ, Wolstenholme AJ, Skehel JJ, Smith MH. The molecular basis of the specific anti-influenza action of amantadine. EMBO J. 1985;4(11):3021-4. Epub19851101. PMID:4065098

12. Dalby $A R$, Iqbal $M$. The European and Japanese outbreaks of $\mathrm{H}_{5} \mathrm{~N} 8$ derive from a single source population providing evidence for the dispersal along the long distance bird migratory flyways. Peer]. 2015;3:e934. http://dx.doi. org/10.7717/peerj.934 PMID:25945320 